УДК 595.754:591.522

DOI 10.18413/2658-3453-2020-2-3-179-184

\title{
РАСПРОСТРАНЕНИЕ И ТРОФИЧЕСКИЕ СВЯЗИ ДУБОВОЙ КРУЖЕВНИЦЫ CORYTHUCHA ARCUATA (SAY) (HETEROPTERA: TINGIDAE) В КРЫMУ
}

\section{DISTRIBUTION AND TROPHIC RELATIONS OF THE OAK LACE BUG CORYTHUCHA ARCUATA (SAY) (HETEROPTERA: TINGIDAE) IN CRIMEA}

\author{
В.Б. Голуб ${ }^{1}$, Н.В. Голуб ${ }^{2}$, В.А. Соболева ${ }^{1}$ \\ V.B. Golub ${ }^{1}$, N.V. Golub ${ }^{2}$, V.A. Soboleva ${ }^{1}$ \\ ${ }^{1}$ Воронежский государственный университет, \\ Россия, 3094018, г. Воронеж, Университетская пл., 1 \\ 2 Зоологический институт РАН, Россия, 199034, г. Санкт-Петербург, Университетская наб., 1 \\ ${ }^{1}$ Voronezh State University, 1 Universitetskaya Sq, Voronezh, 394018, Russia \\ ${ }^{2}$ Zoological Institute, Russian Academy of Sciences, \\ 1 Universitetskaya Emb, St Petersburg 199034, Russia \\ E-mail: v.golub@inbox.ru; nvgolub@mail.ru; strekoza_vrn@bk.ru
}

\begin{abstract}
Аннотация
Для инвазивного вида, клопа дубовая кружевница Corythucha arcuata (Say, 1832) (Heteroptera: Tingidae), по материалам сборов авторов в 2020 г. приводятся два новых пункта его обнаружения в Крыму - Карадагский природный заповедник и лесной массив Агармыш в окрестностях Старого Крыма. В обоих пунктах вид собран на дубе. Описано полное распространение вида в Крыму, с учётом предыдущих публикаций. Сходная по внешнему виду с дубовой кружевницей грушевая кружевница Stephanitis pyri (Fabricius, 1775) в лесу Агармыш заселяет в высокой численности деревья из семейства Rosaceae, а также вяз и дуб.
\end{abstract}

\begin{abstract}
Oak lace bug Corythucha arcuata (Say, 1832) (Heteroptera: Tingidae) was previously known in Crimea from the vicinity of Simferopol and Yalta cities and Sevastopol and Bakhchisarai administrative regions. During the expedition in August 2020, we found an oak lace bug in two more locations: the Karadag Nature Reserve and the Agarmysh forest near the Old Crimea. In first locality, C. arcuata was collected on the leaves of downy oak (Quercus pubescens), in last one - on the rock oak (Q. petraea). Considering the previous indications, a rather wide distribution of the species in the eastern and central parts of southern Crimea is stated. In the Agarmysh forest and on the northern slopes of the Karadag Ridge, another Tingidae species - the polyphagous pear lace bug Stephanitis pyri (Fabricius, 1775), very similar in appearance to the oak lace bug, was found. High numbers of adults and larvae of S. pyri inhabited the crowns of wild pears and apple trees; single individuals were also found on the leaves of oak and elm. C. arcuata was not found on mentioned trees species. The further revision of the trophic relationships of C. arcuata, which is often attributed to polyphagia, is needed.
\end{abstract}

Ключевые слова: дубовая кружевница, Corythucha arcuata, инвазивная, Tingidae, Heteroptera, Крым, новые указания, трофические связи.

Keywords: oak lace bug, Corythucha arcuata, invasive, Tingidae, Heteroptera, Crimea, new indications, trophic connections.

\section{Введение}

Североамериканский клоп дубовая кружевница, или дубовая коритуха, Corythucha arcuata (Say, 1832) (Heteroptera, Tingidae), впервые был обнаружен в Евразии в 2000 г., в Италии, как инвазивный вид, и за неполных два десятка лет он здесь широко распространился. Список стран Евразии, возможно, уже неполный, включает Францию, Италию, Грецию, Швейцарию, Словакию, Венгрию, Словению, Хорватию, Боснию и 
Герцоговину, Румынию, Албанию, Сербию, Болгарию, Турцию, Молдавию, Украину, юг России, Иран [Щуров и др., 2016, 2017, 2019; Neimorovets et al, 2017; Мэшкова, Назаренко, 2020; EPPO Global Database, 2020].

В России вредитель впервые был выявлен в Краснодарском крае в 2015 г. [Щуров и др., 2016]. C. arcuata обладает высокой плодовитостью и способностью быстро расселяться ветром (вид мелкий, очень лёгкий, с широкими тончайшими пластинчатыми паранотумами и такими же чрезвычайно тонкими надкрыльями с пузыревидными образованиями), на перевозимых грузах, в том числе посадочных растениях. Эти качества привели к тому, что дубовая кружевница стала массовым видом и основным вредителем дубрав в Краснодарском крае, Адыгее, западных долинах Республики Карачаево-Черкесия и западной части Республики Абхазия [Щуров и др., 2016, 2017, 2019; Neimorovets et al, 2017; и др.].

Обнаружение вида в Ставропольском крае, в районе Кавказских Минеральных вод, на листьях дуба скального (Quercus petraea (Matt.) Liebl.) пока не сопровождается указанием на его вредоносность на этой территории Северного Кавказа [Мартынов, Никулина, 2019].

\section{Материал и методы исследования}

Сбор материала проводился кошением стандартным энтомологическим сачком по кронам деревьев и кустарников. При укладке на ватные матрасики и фиксировании для последующих кариологических исследований проводился подсчёт собранных экземпляров. Оценка численности грушевой кружевницы на листьях диких груш и яблонь была затруднена ввиду массовости этого вида, фактически не поддающейся учёту, а также из-за постоянного дефицита времени.

Corythucha arcuata (Say, 1832)

Материал. Горный массив Карадаг, Карадагская научная станция им. Т.И. Вяземского - природный заповедник РАН, 2-2.5 км северо-восточнее усадьбы заповедника, юго-западный склон хр. Беш-Таш, вдоль балки Карадагская, 445' с. ш., $35^{\circ} 13^{\prime}$ в. д. 250 м н.у.м., 05.08.2020, на дубе пушистом (Quercus pubescens Willd) (Н. Голуб), 1 ๙ (первое указание для Карадагского заповедника); 2 км западнее г. Старый

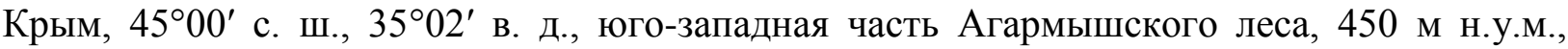
10.08.2020, на дубе скальном (Q. petraea (Matt.) Liebl.), $2{ }^{\lambda}{ }^{\lambda}, 2$ 우 (В. Голуб, В. Соболева).

Stephanitis pyri (Fabricius, 1775)

Материал. Горный массив Карадаг, Карадагская научная станция им. Т.И. Вяземского - природный заповедник РАН, северные склоны Карадагского хребта,

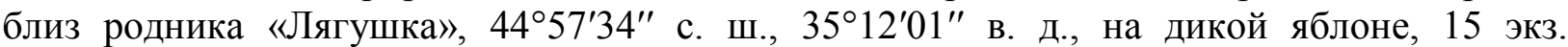

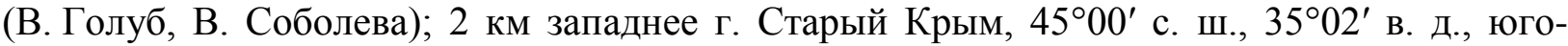
западная часть Агармышского леса, 450 м н.у.м., 10.08.2020, на диких грушах, яблонях, дубе скальном, около 200 экз. (В. Голуб, Н. Голуб, В. Соболева).

Собранный материал хранится в коллекции кафедры зоологии и паразитологии медико-биологического факультета Воронежского государственного университета (г. Воронеж) и в отделении кариосистематики Лаборатории систематики насекомых Зоологического института РАН (г. Санкт-Петербург).

\section{Результаты и их обсуждение}

На территории Республики Крым вид был впервые указан по немногочисленным экземплярам, собранным в 2017 г. на листьях дуба черешчатого Quercus robur L. в окр. Симферополя (посёлок Аграрное) [Стрюкова и др., 2019]. В том же году дубовая коритуха была выявлена в дубраве вблизи древнего пещерного города Эски-Кермен в Бахчисарайском районе. В 2018 г. клоп был зафиксирован на дубе черешчатом и в других пунктах Бахчисарайского района, а также в Севастопольском районе и в Ялте [Стрюкова и др., 2019].

В процессе экспедиции 04-11.08.2020 г. авторами данной статьи дубовая кружевница $C$. arcuata была обнаружена еще в двух пунктах южного Крыма. 
Одновременно с этим видом в тех же пунктах собиралась, фиксировалась и идентифицировалась грушевая кружевница Stephanitis pyri.

Таким образом, по имеющимся и новым указаниям в Крыму вид распространён в его центральной и южной частях: окр. Симферополя, Бахчисарайском районе, близ Севастополя, в Ялте, Карадагском горном массиве и лесном массиве, прилегающем к городу Старый Крым и горе Агармыш. Два последних местонахождения в настоящее время являются самыми восточными в Крыму. Пока невозможно предсказать пути дальнейшего распространения вида в горной и равнинной частях Крыма. Ввиду очень низкой численности в местах обнаружения в Крыму его опасность здесь как вредителя дубрав в настоящее время, очевидно, отсутствует. Тем не менее, необходим постоянный контроль его распространения и численности, особенно в ценных дубовых насаждениях Крыма. Высокая температура и низкая влажность атмосферного воздуха в течение всего лета 2020 г., возможно, служили препятствием для развития вида в высокой численности. Однако ситуация со значением дубовой коритухи в качестве вредителя может измениться. В качестве справочных сведений ниже в краткой форме изложены ранее опубликованные нами [Стрюкова и др., 2019] основные данные о вредоносном значении C. arcuata.

Вредоносность дубовой кружевницы заключается в высасывании клеточных соков из листьев, в результате чего развивается их хлороз, вплоть до полного обесцвечивания, и в загрязнении листьев экскрементами и экзувиями личинок. В результате питания кружевниц нарушаются ассимиляционные процессы, листья преждевременно опадают, что отрицательно влияет на закладку почек на будущий год. Особую опасность представляет снижение фотосинтетической активности листьев, что является причиной угнетения и гибели дубов [Стрюкова и др., 2019].

Дубовая кружевница вредит, в основном, различным видам дуба (Quercus spp.). Кроме того, в качестве кормовых растений указывались каштан американский (Castanea dentata), виды клёна (Acer spp.), яблони (Malus spp.), шиповника (Rosa spp.), ежевики (Rubus spp.) и малина ( $R$. idaeus) и другие деревья и кустарники из ряда семейств. Указания на другие виды растений в качестве кормовых, кроме дуба и каштана, требуют подтверждения в связи с тем, что, например, на деревьях и кустарниках из Rosaceae в высокой численности развивается внешне сходный вид - грушевая кружевница Stephanitis pyri. Внешне эти два мелких вида (2.8-3.2 мм) очень сходны (рис. 1), и безошибочная идентификация собранных особей невозможна без использования оптических приборов со значительным увеличением в лабораторных условиях.

Нами разработан специальный иллюстрированный ключ с оригинальными фотографиями и подписями деталей строения для определения дубовой кружевницы C. arcuata, живущего на платане близкого вида - платановой кружевницы C. ciliata (Say, 1832), и грушевой кружевницы S. pyri [Golub, Soboleva, 2018]. В отношении трофических связей грушевой кружевницы давно и хорошо известно, что она питается и успешно развивается на целом ряде видов деревьев и кустарников из разных семейств [Пучков, 1974; Péricart, 1983].

При проверке возможности питания дубовой кружевницы на различных видах деревьев установлено, что на склонах Карадагского горного массива, помимо единичных особей $C$. arcuata на двух породах дуба (пушистом и скальном), были обнаружены очаги грушевой кружевницы в высокой численности на диких яблоне и груше (рис. 2), а в Агармышском лесном массиве - единичные особи на вязе. При этом на дубе скальном грушевая кружевница также обнаружена, хотя и в единичных экземплярах. Таким образом, по нашим наблюдениям, на дубе живут оба вида, а на других обследованных видах - только S. pyri. Результаты данного исследования неопровержимо свидетельствуют о необходимости пересмотра трофических связей дубовой кружевницы и тщательной идентификации собранного материала на разных видах деревьев при её выявлении и исследовании вредоносного значения. 


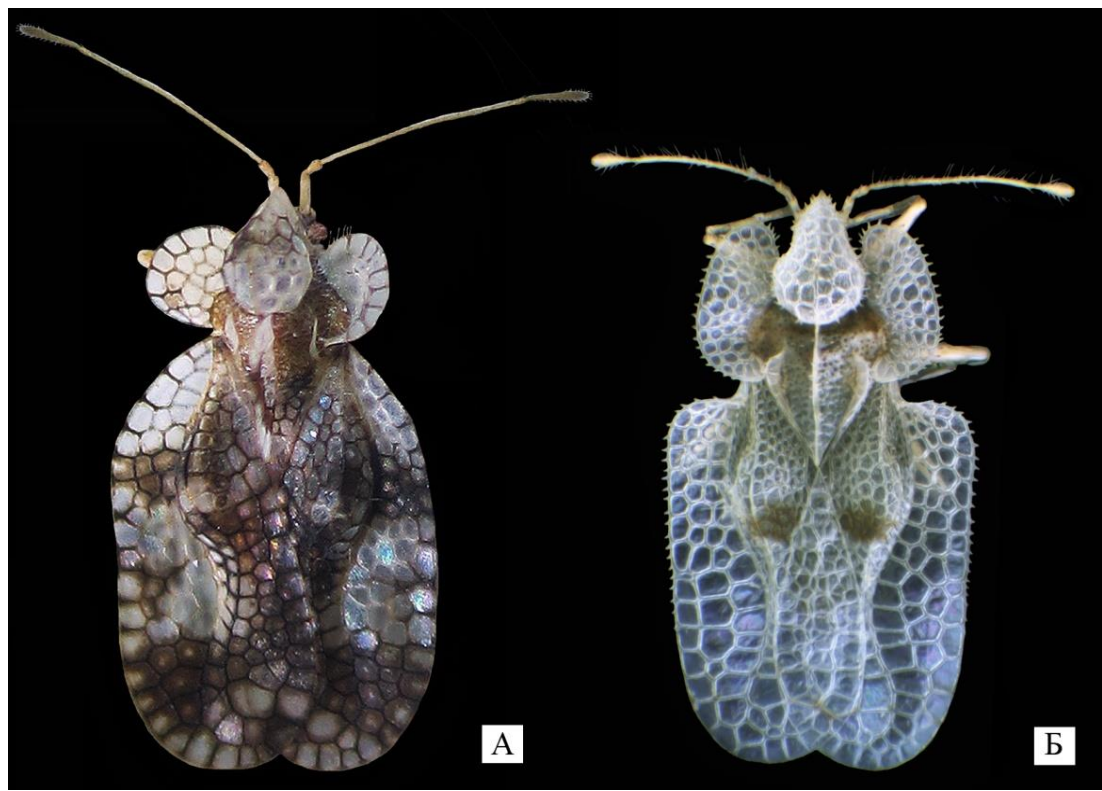

Рис. 1. Грушевая и дубовая кружевницы:

А - грушевая кружевница Stephanitis pyri (Fabricius, 1775);

Б - дубовая кружевница Corythucha arcuata (Say, 1832) [по: Golub, Soboleva, 2018]

Fig. 1. Pear and oak lace bugs:

A - pear lace bug Stephanitis pyri (Fabricius, 1775);

B - oak lace bug Corythucha arcuata (Say, 1832) [by Golub, Soboleva, 2018]
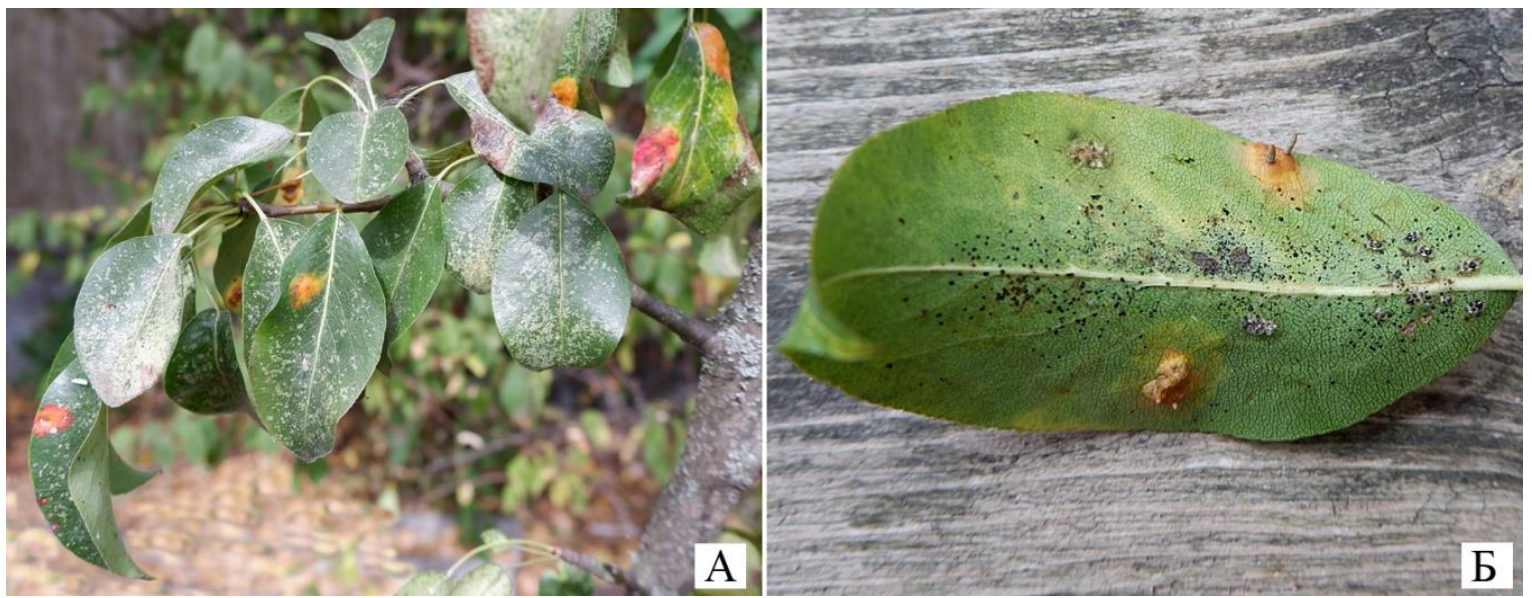

Рис. 2. Листья груши, заселённые грушевой кружевницей Stephanitis pyri (Fabricius, 1775)

(лес Агармыш в окрестностях Старого Крыма, 2020 г., фото авторов).

А - общий вид листьев с повреждениями грушевой кружевницы; Б - нижняя поверхность листа груши с имаго и личинками грушевой кружевницы и их испражнениями

Fig. 2. Leaves inhabited by pear lace bug Stephanitis pyri (Fabricius, 1775)

(Agarmysh forest in the vicinity of the Old Crimea, 2020, photo by authors):

A - general view of leaves with damages of pear lace bug; B - the lower surface of a pear leaf with imago and larvae of pear lace bug and their excrement

\section{Выводы}

1. Дубовая кружевница ( $C$. arcuata) довольно широко распространена на юге восточной части Крыма и, частично, на его центральной территории.

2. Численность дубовой кружевницы в пунктах её обнаружения в Крыму в настоящее время низкая.

3. Во всех пунктах обнаружения нами и предыдущими авторами дубовой кружевницы в Крыму вид заселял только разные породы дуба - черешчатого, пушистого и скального. На других видах, кроме дуба, C. arcuata в Крыму не обнаружен. 
4. Кроме дубовой кружевницы, в пунктах её выявления развивается полифаг грушевая кружевница (S. pyri). Последний вид в массовой численности встречался на деревьях из семейства Rosaceae (груше, яблоне), в низкой численности - на дубе и вязе.

5. В связи с очень высоким внешним сходством C. arcuata и $S$. pyri необходим пересмотр трофических связей дубовой кружевницы, для которой в качестве кормовых растений разными авторами указывался целый ряд видов деревьев и кустарников, в том числе из семейства Rosaceae.

\section{Благодарности}

Авторы выражают благодарность директору Карадагской научной станции имени Т.И. Вяземского - природного заповедника - филиала Федерального исследовательского иентра «Институт биологии южных морей имени А.О. Ковалевского РАН» В.А. Литвину, всему руководству и работникам Отдела государственной охраны заповедника за содействие при проведении экспедиционных работ.

Работа выполнена при финансовой поддержке РФФИ (грант 18-04-00464-а) (В.Б. Голуб, Н.В. Голуб, В.А. Соболева) и в рамках государственной темы № АAАA-А19119020790106-0 (Н.В. Голуб).

\section{Список литературы}

1. Мартынов В.В., Никулина Т.В. 2019. Первая находка дубовой кружевницы Corythucha arcuata (Say, 1832) (Hemiptera: Tingidae) в Ставропольском крае. B кн.: Итоги и перспективы развития энтомологии в Восточной Европе. Сборник статей III Международной научнопрактической конференции, посвященной памяти Вадима Анатольевича Цинкевича (1971-2018) (г. Минск, 19-21 ноября 2019 г.). Минск, Издатель А.Н. Вараксин: 245-247.

2. Мэшкова В., Назаренко С. 2020. Маленький клоп-мереживниця загрожує дубовим лісам. Лісовий і Мисливський журнал, 3: 10-12.

3. Пучков В.Г. 1974. Фауна України. Т. 21, вип. 4. Беритиди, Червоноклопи, Піэзматиди, Підкорники, Тингіди. Київ, Наукова Думка, 332 с.

4. Стрюкова Н.М., Омельяненко Т.З., Голуб В.Б. 2019. Дубовая кружевница в Республике Крым. Защита и карантин растений, 9: 43-44.

5. Щуров В.И., Бондаренко А.С., Скворцов М.М., Щурова А.В. 2016. Чужеродные инвазивные виды насекомых-фитофагов, впервые выявленные в древесно-кустарниковых сообществах СевероЗападного Кавказа в 2014-2016 годах. В кн.: Дендробионтные беспозвоночные животные и грибы и их роль в лесных экосистемах. Материалы международной конференции IX Чтения памяти О.А. Катаева (г. Санкт-Петербург, 23-25 ноября 2016 г.). СПбГЛТУ: 134-135.

6. Щуров В.И., Бондаренко А.С., Скворцов М.М., Щурова А.В. 2017. Чужеродные насекомые - вредители леса, выявленные на Северо-Западном Кавказе в 2010-2016 годах, и последствия их неконтролируемого расселения. Известия Санкт-Петербургской лесотехнической академии, 220: 212-228.

7. Щуров В.И., Замотайлов А.С., Скворцов М.М., Щурова А.В., Белый А.И. 2019. Оценка популяционных характеристик адвентивных насекомых-фитофагов (Insecta: Heteroptera, Coleoptera, Hymenoptera, Lepidoptera) в лесах Северо-Западного Кавказа: практика 2010-2019 годов. Труды Кубанского государственного аграрного университета, 4 (79): 135-158.

8. Golub V.B., Soboleva V.A. 2018. Morphological differences between Stephanitis pyri, Corythucha arcuata and C. ciliata (Heteroptera: Tingidae) distributed in the south of the European part of Russia. Zoosystematica Rossica, 27 (1): 142-145.

9. EPPO Global Database. 2019. Corythucha arcuata. Available at: https://gd.eppo.int/taxon/CRTHAR/distribution. (accessed 31 August 2020)

10. Neimorovets V.V., Shchurov V.I., Bondarenko A.S., Skvortsov M.M., Konstantinov F.V. 2017. First documented outbreak and new data on the distribution of Corythucha arcuata (Say, 1832) (Hemiptera: Tingidae) in Russia. Acta Zooligica Bulgarica, suppl. 9: 139-142.

11. Péricart J. 1983. Hémiptères Tingidae euroméditerranéens. Faune de France, 69. Paris: FFSSN: 1-620. (in French) 


\section{References}

1. Martynov V.V., Nikulina T.V. 2019. Pervaya nakhodka dubovoy kruzhevnitsy Corythucha arcuata (Say, 1832) (Hemiptera: Tingidae) v Ctavropol'skom kraye [The first find of the oak lace bug Corythucha arcuata (Say, 1832) (Hemiptera: Tingidae) in the Stavropol Territory]. In: Itogi i perspektivy razvitiya entomologii $\mathrm{v}$ Vostochnoy Evrope [Results and prospects for the development of entomology in Eastern Europe]. Collection of articles of the III International Scientific and Practical Conference dedicated to the memory of Vadim Anatolyevich Tsinkevich (1971-2018) (Minsk, November 19-21, 2019). Minsk, Publisher A.N. Varaksin: 245-247.

2. Meshkova V., Nazarenko S. Small lace bug damages oak forests. Forest and Hunting Journal, 3: 10-12. (in Ukrainian)

3. Putshkov V.G. 1974. Fauna Ukraïny. T. 21, vyp. 4. Berytydy, Chervonoklopy, Piézmatydy, Pidkornyky, Tynhidy [Fauna of Ukraine. T. 21, Vol. 4. Berytidae, Pyrrhocoridae, Piesmatidae, Aradidae, Tingidae]. Kiev, Naukova Dumka, 332 p. (in Ukrainian)

4. Stryukova N.M., Omelianenko T.Z., Golub V.B. 2019. Oak lace bug in the Republic of Crimea. Zashchita i karantin rasteniy, 9: 43-44. (in Russian)

5. Shchurov V.I., Bondarenko A.S., Skvortsov M.M., Shchurova A.V. 2016. Chuzherodnyye invazivnyye vidy nasekomykh-fitofagov, vpervyye vyyavlennyye $\mathrm{v}$ drevesno-kustarnikovykh soobshchestvakh Severo-Zapadnogo Kavkaza v 2014-2016 godakh [Alien invasive phytophagous insect species first identified in tree and shrub communities of the Northwestern Caucasus in 2014-2016]. In: Dendrobiontnyye bespozvonochnyye zhivotnyye i griby i ikh rol' v lesnykh ekosistemakh [Dendrobiontic invertebrates and fungi and their role in forest ecosystems]. Materials of the international conference IX Readings in memory of O. Kataeva (St. Petersburg, 23-25 November 2016). SPbGLTU: 134-135.

6. Shchurov V.I., Bondarenko A.S., Skvortsov M.M., Shchurova A.V. 2017. Alien forest insect pests revealed in the Northwest Caucasus in 2010-2016 and consequences of their uncontrolled dispersal. Izvestia Sankt-Peterburgskoj Lesotehniceskoj Akademii, 220: 212-228. (in Russian with English summary)

7. Shchurov V.I., Zamotajlov A.S., Skvortsov M.M., Shchurova A.V., Belyi A.I. 2019. Study on population characteristics of the alien phytophage insect species (Insecta: Heteroptera, Coleoptera, Hymenoptera, Lepidoptera) in forests of the Northwestern Caucasus: 2010-2019 practice. Trudy Kubanskogo gosudarstvennogo agrarnogo universiteta, 4 (79): 135-158. (in Russian)

8. Golub V.B., Soboleva V.A. 2018. Morphological differences between Stephanitis pyri, Corythucha arcuata and $C$. ciliata (Heteroptera: Tingidae) distributed in the south of the European part of Russia. Zoosystematica Rossica, 27 (1): 142-145.

9. EPPO Global Database. 2019. Corythucha arcuata. Available at: https://gd.eppo.int/taxon/CRTHAR/distribution. (accessed 31 August 2020)

10. Neimorovets V.V., Shchurov V.I., Bondarenko A.S., Skvortsov M.M., Konstantinov F.V. 2017. First documented outbreak and new data on the distribution of Corythucha arcuata (Say, 1832) (Hemiptera: Tingidae) in Russia. Acta Zooligica Bulgarica, suppl. 9: 139-142.

11. Péricart J. 1983. Hémiptères Tingidae euroméditerranéens. Faune de France, 69. Paris: FFSSN: 1-620. (in French)

Поступила в редакиию 09.09.2020

\section{Ссылка для цитирования статьи For citation}

Голуб В.Б., Голуб Н.В., Соболева В.А. 2020. Распространение и трофические связи дубовой кружевницы Corythucha arcuata (Say) (Heteroptera: Tingidae) в Крыму. Полевой журнал биолога, 2 (3): 179-184. DOI 10.18413/2658-3453-2020-2-3-179-184

Golub V.B., Golub N.V., Soboleva V.A. 2020. Distribution and Trophic Relations of the Oak Lace Bug Corythucha arcuata (Say) (Heteroptera: Tingidae) in Crimea. Field Biologist Journal, 2 (3): 179-184. DOI 10.18413/2658-3453-2020-2-3-179-184 